\title{
Use of Nandrolone Decanoate in Treatment of Pure Red Cell Aplasia Secondary to Diclofenac Administration: A Case Report
}

\author{
Paula Nassar de Marchi, MSc a, André Nanny Le Sueur Vieira, MV \\ José Francisco Antunes Ribeiro, MV ${ }^{\mathrm{a}}$, Silvano Salgueiro Geraldes, MV \\ Paulo Roberto Rodrigues Ramos, PhD ${ }^{\mathrm{b}}$, Alessandra Melchert, PhD ${ }^{\mathrm{a}}$, \\ Priscylla Tatiana Chalfun Guimarães-Okamoto, $\mathrm{PhD}^{\mathrm{a}, *}$
}

Keywords:

aplasia

dogs

immune-mediated hemolytic anemia

nandrolone decanoate

${ }^{a}$ Veterinary Clinic Department, School of Veterinary Medicine and Animal Science, São Paulo State University-UNESP, São Paulo,

Brazil

${ }^{b}$ Physics and Biophysics Department, Institute of Bioscience, São Paulo State UniversityUNESP, São Paulo, Brazil

*Address reprint requests to: Priscylla Tatiana Chalfun Guimarães-Okamoto, PhD, Veterinary Clinic Department, School of Veterinary Medicine and Animal Science, Rubião Júnior District, 18618-681, Botucatu, São Paulo, Brazil.

E-mail: tatiana@fmvz.unesp.br

(P.T.C. Guimarães-Okamoto)
Pure red cell aplasia (PRCA) is a disorder that leads to a nonregenerative anemia that results from erythroid precursors failing to reach maturity in the bone marrow, whereas the numbers of mature myeloid and megakaryocytic cells remain normal. PRCA can be induced by autoimmune processes, infections, drugs, toxins, and radiation, and is diagnosed by a bone marrow cytology examination after excluding the most common causes of nonregenerative anemia. Immunosuppressive therapies are used to treat PRCA, and usually involve the use of glucocorticoids, cyclosporin, or azathioprine. Alternatively, although little studied in veterinary medicine, drugs which stimulate bone marrow (e.g., nandrolone decanoate) have been mentioned as possible therapeutic agents. A case of PRCA that presented at the Veterinary Teaching Hospital of the Faculty of Veterinary Medicine and Animal Science (UNESP)Botucatu, Brazil showed a good therapeutic response to weekly administration of nandrolone decanoate. Therefore, it was concluded that bone marrow stimulants might improve the quality of life of PRCA patients, provided they are used with caution and under close clinical supervision.

(c) 2017 Elsevier Inc. All rights reserved.

\section{Introduction}

Pure red cell aplasia (PRCA) is characterized by reduced numbers of red blood cells in peripheral blood, due to hypoplasia of erythroid precursors or the failure of erythroid cells to properly mature in bone marrow, whereas the myeloid and megakaryocytic cells remain unaffected. ${ }^{1}$

PRCA can be caused by the same factors that cause aplasia or hypoplasia, and include antibiotics, antiviral agents, anticonvulsants, anti-inflammatories, diuretics, and estrogens. ${ }^{2,3}$ Furthermore, certain immune-mediated disorders, infections, toxic reactions, types of radiation, and idiopathic causes can induce PRCA. ${ }^{1,4}$

PRCA is initially diagnosed based on laboratory findings indicative of chronic severe, progressive, normocytic, and normochromic anemia of sudden onset. Couto ${ }^{1}$ reported that macrocytosis is found in cats with PRCA, and is associated with feline immunodeficiency and feline leukemia virus infections. Discrete microcytosis is a persistent finding in dogs, and is accompanied by the presence of spherocytes, as well as a positive direct Coombs test when the cause is directly related to an autoimmune disorder. Weiss and Klausner (2008) found that hematological patients (dogs) diagnosed with PRCA had a mean hematocrit of $\sim 8 \pm 2 \%$, and erythroid cells were the only type of cells affected.

Bone marrow disease should be suspected when all other causes of chronic anemia have been excluded for explaining changes observed in peripheral blood. In such cases, the patient should be subjected to a bone marrow aspiration, and the extracted marrow should be examined by cytology. ${ }^{4}$ The bone marrow evaluation may reveal erythroid production accompanied by a selective reduction in erythroid precursors. ${ }^{5}$ Furthermore, there is usually a significant increase in the myeloid-to-erythroid ratio (M:E) to a level > 3:1. Moreover, there is usually no evidence on ongoing dysplastic or neoplastic processes. ${ }^{6}$

Treatment of PRCA focuses on resolving its underlying cause, and due to its immune-mediated features, treatment usually consists of an immunosuppressive therapy. Blood transfusions may be needed in patients with severe anemia. Initially, an immunosuppressive dose of glucocorticoids should be established (e.g., dexamethasone, prednisone, and prednisolone at higher doses), and cyclosporine can also be used. ${ }^{4,6}$ Azathioprine can be given at a dose of $2 \mathrm{mg} / \mathrm{kg}$ every 24 hours.

Although their efficacy has not been well studied in dogs, erythropoiesis-stimulating agents such as all-trans retinoic acid, ${ }^{8}$ oxymetholone, thymomodulin, ${ }^{9}$ and nandrolone, ${ }^{10}$ can also be administered in cases where immunosuppressants do not provide the expected therapeutic effect. Nandrolone decanoate is a synthetic androgen with anabolic effects, and is capable of stimulating cell growth and resistance. ${ }^{10,11}$

Here, we report a case of PRCA secondary to diclofenac administration, and describe alternative therapeutic possibilities when immunosuppressive drugs fail to elicit a satisfactory clinical response. 


\section{Case Description}

A 7-year-old male, mixed-breed dog admitted at the Veterinary Teaching Hospital of UNESP in Botucatu, Brazil, with a history of diclofenac administration (50 mg every 12 hours for 13 days) as treatment of inflammation caused by trauma to the right eye region. The animal was presented with emesis, hematochezia, anorexia, and prostration, which can be symptoms of hemorrhagic gastroenteritis.

The patient received supportive treatment that included fluid therapy, antiemetic drugs, antibiotics, enteral nutrition, and gastric protectors. Although the patient's clinical condition (e.g., appetite, physical activity level, emesis frequency, and hematochezia) improved after initiation of therapy, the $\mathrm{CBC}$ results continued to show a persistent nonregenerative anemia, even after resolution of the hemorrhagic gastroenteritis. Nonregenerative anemia was confirmed by a reticulocyte count of $25,600 / \mu \mathrm{L}$; which indicated a lack of bone marrow response.

The blood analyses, such as the CBCs, were performed using a PocH-100iV-Diff hematology analyzer, and the results were confirmed manually. The results suggested a nonregenerative anemia (hematocrit of 19\%), whereas the other analytes (total protein, platelets, and WBCs) were within their normal ranges. After excluding several differential diagnoses, the results of biochemical tests and a urinalysis also made it possible to exclude anemia due to kidney diseases.

From day 0 , which diclofenac was first given; on the day 16 , our initial therapeutic approach was based on the oral administration of ferrous sulfate (250 mg every 24 hours) and prednisone ( $2 \mathrm{mg} / \mathrm{kg}$ every 12 hours), followed by a gradual reduction of those doses based on the results of weekly hematological tests. On day 16, the patient had a hematocrit of $12 \%$ and total protein concentration of $6.2 \mathrm{~g} / \mathrm{dL}$. After starting treatment, the hematocrit values ranged from $17 \%-22 \%$ and the total protein concentration was $6.2 \mathrm{~g} / \mathrm{dL}$. After 1 week of treatment (day 32 ), the hematocrit rose from $12 \%$ $21 \%$, indicating significant improvement.

One possible cause of anemia that had to be considered was babesiosis. Even though capillary blood test (from the tip of the patient's ear) presented negative for babesiosis, we began giving to the patient intramuscular injections of imidocarb (2 doses of $3.5 \mathrm{mg} / \mathrm{kg}$ in a 15-day interval). Despite of the poor clinical improvement of the patient and $\mathrm{CBC}$ failed to show satisfactory responses to treatment, babesiosis was eliminated as the cause of anemia.

Moreover, serum concentrations of triglycerides, cholesterol, and glucose ruled out any possible endocrine comorbid disorder. Results of a saline slide agglutination test were negative ruling out immune-mediated hemolytic anemia. The patient also underwent imaging studies that included an abdominal ultrasound and chest radiography to search for signs of neoplasia and metastases; however, the results were negative.

A bone marrow cytology and histopathology was performed and specific analysis revealed hypoplasia of the erythroid series, accompanied by a reduction in mature erythroid forms (e.g., metarubricytes), suggesting a disruption in the maturation erythroid precursor cells. The histopathologic examination of the bone marrow (Fig 1) revealed that the megakaryocytic series exhibited a slight degree of dyspoiesis, as well as decreased overall cellularity (20\%).

These findings were confirmed by cytology results that also revealed a lower degree of cellularity (20\%) than would be predicted based on the animal's age (Fig 2). The decreased cellularity was due to mild hypoplasia of the myeloid and erythroid series, with the erythroid series showing reduced numbers of mature forms or the effects of a recent bone marrow reserve depletion.

Despite of the unsatisfactory hematocrit response with the prescription of prednisone at immunosuppressive dose, on day 64, azathioprine was added to the treatment ( $2 \mathrm{mg} / \mathrm{kg}$ every 24 hours) as an attempt to gradually replace prednisone. Unfortunately, the patient's laboratorial examinations demonstrated minimal changes, with only a $2 \%$ hematocrit improvement, which subsequently lowered back to $17 \%$ three weeks later (day 85 ).

On day 92, nandrolone decanoate $(1.2 \mathrm{mg} / \mathrm{kg}$ intramuscular), was administrated once a week. The patient's hematocrit notably increased from an initial level of $17 \%$ to a final value of $26 \%$ on the seventh day of treatment. Additionally, the patient's appetite, weight, and activity level were also improved. After correlating
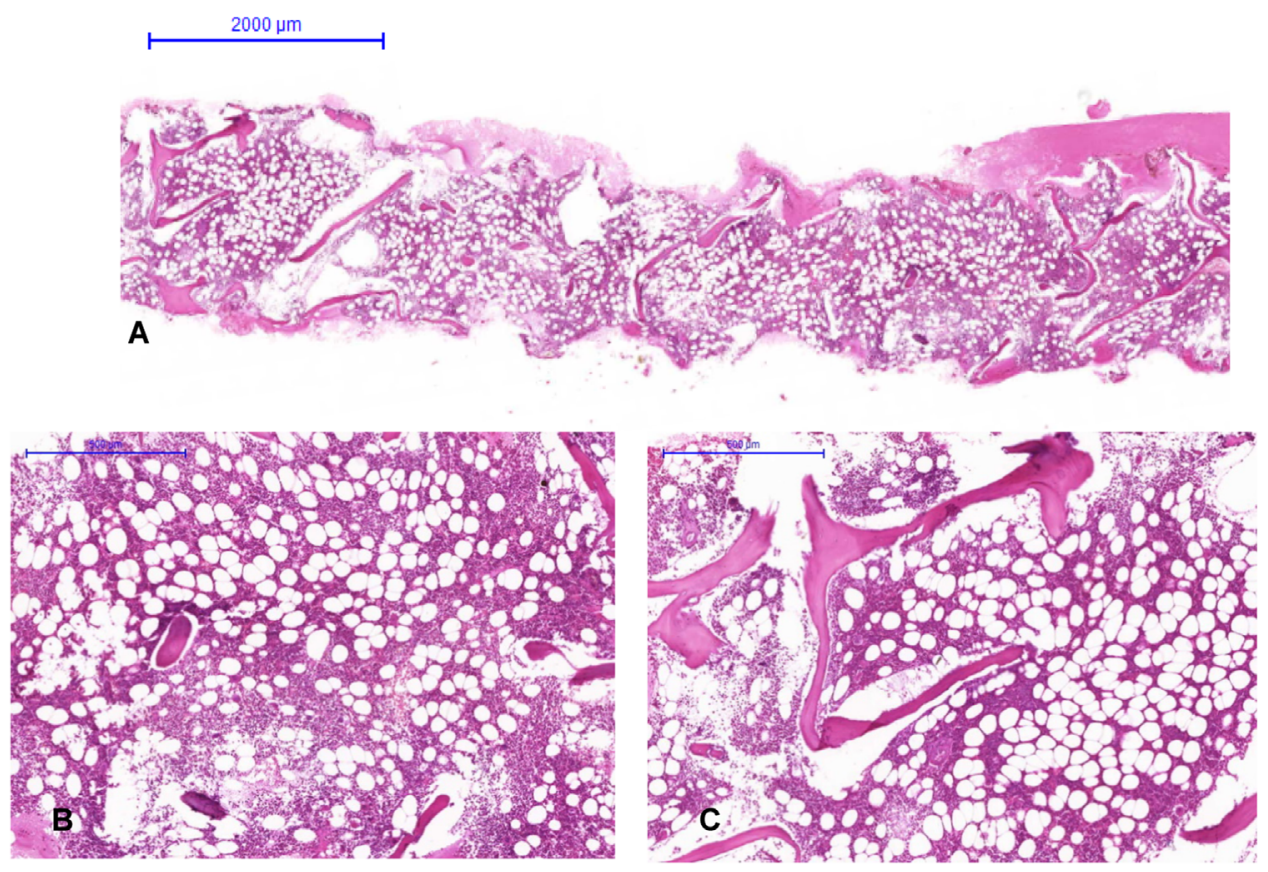

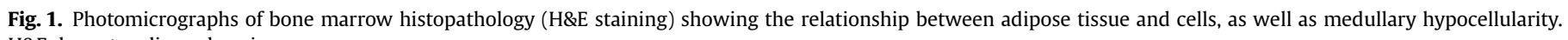
$\mathrm{H} \& \mathrm{E}$, hematoxylin and eosin. 


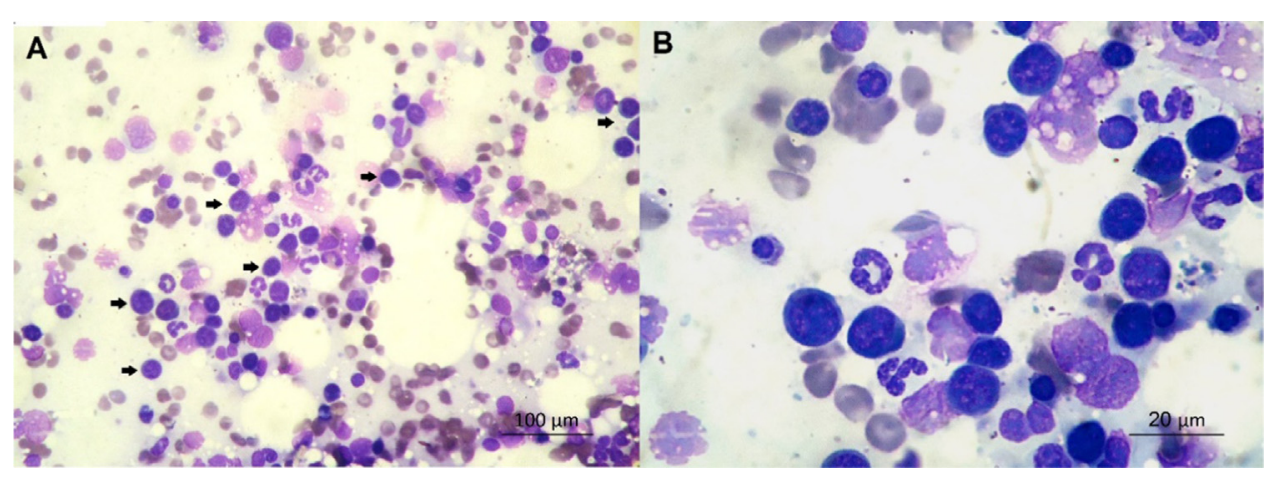

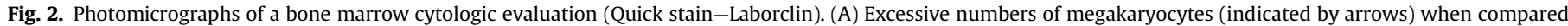
to the numbers of mature cells. (B) Predominance of megakaryocytes when compared to mature cells.

the dog's hematological data with its response to different therapies, it was remarkable that the best therapeutic response occurred when a marrow stimulant (nandrolone decanoate) was added to the treatment protocol. Therefore, we continued to administer an intramuscular dose of nandrolone decanoate $(1.2 \mathrm{mg} / \mathrm{kg}$, once a week) for the following 8 weeks, and observed substantial improvements in the dog's hematologic parameters.

On the eighth week of treatment of nandrolone decanoate, we obtained a maximum hematocrit of $28 \%$, whereas the maximum total protein concentration $(6.6 \mathrm{~g} / \mathrm{dL})$ was achieved by the fourth week. After the prescription of 8 doses of nandrolone decanoate, the dog's owner decided to cease the treatment due to the great improvement of the patient.

Subsequently, after 6 weeks without it is treatment, a CBC recheck was performed and the dog's hematologic data showed a $27 \%$ hematocrit and $6.2 \mathrm{~g} / \mathrm{dL}$ total protein concentration and history of weight gain. After achieving a stable $\mathrm{CBC}$, and a gain in body weight, the owner decided to discontinue the patient's treatment.

\section{Discussion}

Even though immune-mediated hemolytic anemia is usually a regenerative disorder, it can be confused with medullary disorders. PRCA is often secondary to an immune-mediated disorder, and can be considered as a type of nonregenerative hemolytic anemia, due to the occurring autoimmune attack against erythroid precursors. $^{7}$

The etiology of PRCA is wide; and therefore, cannot always be determined. In this case, the patient has received a high-dose of diclofenac for 13 days, which may have led to an erythroid suppressive condition. After thoroughly examining the animal's medical history to identify a possible cause for this condition, high-dose diclofenac was the only factor that could explain the bone marrow hypoplasia.

PRCA is primarily treated with immunosuppressants., ${ }^{4,6}$ Brandão et $\mathrm{al}^{8}$ recommended the administration of prednisone $(2 \mathrm{mg} / \mathrm{kg}$ every 12 hours) and azathioprine ( $2 \mathrm{mg} / \mathrm{kg}$ every 24 hours) in the treatment of nonregenerative immuno-mediated hemolytic anemia. Those doses were like the doses prescribed in this case report. However, unlike the outcome in Brandão's case, our patient did not achieve a good result with that therapy.

Our initial use of immunosuppressive therapy produced a clinical improvement in the patent. The patient energy level and clinical signs remained normal and showed no further gastroenteric symptoms. While the patient showed some slight hematologic improvement after starting immunosuppressive therapy (hematocrit rose from $12 \%-22 \%$ ), the improvement stagnated after 4-5 weeks of treatment, as the hematocrit returned to $17 \%$.
Therefore, we initiated the weekly intramuscular administration of nandrolone decanoate $(1.2 \mathrm{mg} / \mathrm{kg})$. This treatment was effective, hematocrit rose from $17 \%-28 \%$, and no adverse side effects were observed. Our results agree with findings reported from a study conducted by Perez et $\mathrm{al}^{10}$, who evaluated the efficacy of nandrolone decanoate as an erythropoiesis-stimulating agent in rats with bone marrow suppression induced by myelotoxic chemotherapy (vincristine sulfate). In that study, efficacy was observed in patients with mild bone marrow depression after they received a single intramuscular dose of nandrolone decanoate $(1.5 \mathrm{mg} / \mathrm{kg})$. In this study, we evaluated the effects of nandrolone decanoate when administered at only 1 dose $(1.2 \mathrm{mg} / \mathrm{kg})$. Therefore, additional studies are needed to determine the optimal dose and dosing frequency for this drug when it is used as a bone marrow stimulant.

\section{Conclusion}

Bone marrow hypocellularity may result from the action of drugs (e.g., chemotherapy, phenylbutazone, fenbendazole, sulfonamides, NSAIDs, estrogen, and toxins [e.g. aflatoxin B1]). A bone marrow examination is required to definitively diagnose hypocellularity, and especially when no apparent hematological cause can be identified. Furthermore, a full evaluation should be performed to search for any possible etiology of bone marrow suppression. In cases with little or irresponsive to immunosuppressive therapy, synthetic androgens can be given as marrow stimulants. The owner should have the patient's hematological parameters re-assessed on a weekly basis to allow for better stabilization.

\section{References}

1. Couto CG. Anemia. In: Nelson RW, Couto CG, editors. Medicina Interna de Pequenos Animais. 4th ed. Rio de Janeiro: Elsevier; 2010. p. 1211-1225

2. Weiss DJ, Klausner JS. Drug associated aplastic anemia in dogs: eight cases (1984-1988). J Am Vet Med Assoc 196:472-475, 1990

3. Hart S, Nolte I. Long-term treatment of diseased, FIVseropositive field cats with Azidothymidine (AZT). J Vet Med A Physiol Pathol Clin Med 42:397-409, 1995

4. Moraes LF, Takahira RK. Aplasia medular em cães. Rev Ciên Agrovet 9:99-108, 2010

5. Weiss DJ. Bone marrow pathology in dogs and cats with non-regenerative immune-mediated haemolytic anaemia and pure red cell aplasia. J Comp Pathol 138:46-53, 2008

6. Doherty T, Austin SK, Newell B, Kiely PDW. Mycophenolate mofetil-induced erytrhoid hypoplasia in a patient with systemic lupus erythematosus. Lupus 22:213-215, 2013

7. Viviano KR, Webb JL. Clinical use of cyclosporine as an adjunctive therapy in the management of feline idiophatic pure red cell aplasia. J Feline Med Surg 13:885-895, 2011

8. Brandão LP, Ikesaki JH, Miyashiro SI, Franchini ML, Hagiwara MK. Anemia hemolítica imunomediada não regenerativa em um cão. Cienc Rural 34:557-561, 2004 
9. Pallota R. Diagnostic methodology and treatment of relapse after bone marrow transplantation in a patient with acute promyelocitic leukemia. Rev Bras Hematol Hemoter 22:414-418, 2000

10. Perez RR, Silva MAML, Varzim FLSB, Oliveira SB, Hucke EETS. A ação do decanoato de nandrolona (Deca-Durabolinß) sobre parâmetros hematológicos e proteína total de ratos (Rattus rattus) com depressão medular induzida após administração de sulfato de vincristina (Oncovin (R)). Cienc Rural 35:589-595, 2005

11. Larsson CE. Terapêutica tópica e sistêmica: pele, ouvido e olho. In: Andrade SF, editor. Manual de terapêutica veterinária. 2nd ed. São Paulo: Roca; 2002. p. $116-178$ 